\title{
Kayın Mantarı (Pleurotus ostreatus) Genomunda Bulunan ABC Proteinlerinden MDR Alt Ailesinin Biyoinformatik Analizi ve İfade Profili
}

\author{
Hatice Kübra DÜZEL ${ }^{1}$, Birsen ÇAKIR AYDEMİR ${ }^{*}$ \\ ${ }^{1}$ Ege Üniversitesi, Fen Bilimleri Enstitüsü, Biyoteknoloji Anabilim Dalı, Bornova, İzmir, Türkiye, \\ ${ }^{2}$ Ege Üniversitesi, Ziraat Fakültesi, Bahçe Bitkileri Bölümü, Bornova, İzmir, Türkiye \\ *Sorumlu Yazar/Corresponding Author \\ Araştırma Makalesi/Research Article \\ E-mail: birsen.cakir@ege.edu.tr \\ Gelis Tarihi/Received: 02.11.2021 \\ Orcid ID: 0000-0003-4268-8547 \\ Kabul Tarihi/Accepted: 28.11 .2021
}

\section{ÖZET}

Hücre zarında birçok farklı metabolik yolu kontrol eden yapılardan biri olan ve en büyük protein ailelerinden birini oluşturan ATP bağlayan kaset taşıyıcı proteinleri (ABC) ATP enerjisini kullanarak madde taşınımında görev alırlar. Çözünür $\mathrm{ABC}$ proteinleri transmembran taşınmasına dahil değildir, ancak hücresel süreçlerde, örneğin ribozom biyojenezi ve mRNA translasyonunda önemli bir rol oynamaktadır. $\mathrm{ABC}$ proteinlerinin bir alt ailesi olan çoklu ilaç direnci (MDR) alt ailesi, antimikrobiyal peptitler, lipit taşınması, feromon taşınması, mitokondriyal porfirin alımı, ökaryotik peptit taşınması, antijenlerin işlenmesi, oksidatif stresden korunma, ağır metal dayanıklılığı, v.b. olaylarda rol oynamaktadır. Bu çalışmada kayın mantarı (Pleurotus osteradus) genomunun biyoinformatik analizi ile $\mathrm{ABC}$ proteinlerinin bir alt üyesi olan $\mathrm{ABCB}$ gen ailesine ait 8 tane MDR protein kodlayan gen (PoMDRs) belirlenmiştir. PoMDRs genlerinin kodladığı proteinler ile filogenetik ağaç oluşturulmuştur. Ayrıca bu çalışma kapsamında ilk defa sap ve şapkada PoMDR genlerinin ifade seviyeleri incelenmiş ve bu genlerin ifade düzeylerinin benzer profillere sahip oldukları ancak bu genlerin ifade seviyelerinin şapkada daha fazla olduğu tespit edilmişsir.

Anahtar Kelimeler: ABC kaset taşıyıcıları, MDR alt ailesi, mRNA ifadesi, Pleurotus ostreatus, Kayın mantarı

\section{Bioinformatic Analysis and Expression Profile of MDR Subfamily of ABC Proteins from Oyster Mushroom (Pleurotus ostreatus) Genome}

\begin{abstract}
ATP-binding cassette proteins $(\mathrm{ABC})$, one of the largest protein families involved in the transport of substances by consuming ATP in many different metabolic reactions in the cell membrane. Soluble ABC proteins, on the other hand, are not involved in transmembrane transport, but play an important role in cellular processes, such as ribosome biogenesis and mRNA translation. Multidrug resistance (MDR) subfamily, which is a subfamily of $\mathrm{ABC}$ proteins, plays a role in the transport of antimicrobial peptides, lipid transport, pheromone transport, mitochondrial porphyrin uptake, multidrug resistance, eukaryotic peptide transport, antigen processing, protection from oxidative stress, heavy metal resistance, etc. In this study, $8 \mathrm{MDR}$ protein-coding genes (PoMDRs) belonging to the $\mathrm{ABCB}$ gene family, which is a sub-class of $\mathrm{ABC}$ proteins, were determined by bioinformatic analysis of the beech mushroom (Pleurotus osteradus) genome. And a phylogenetic tree was formed with the proteins encoded by these genes. In addition, within the scope of this study, the expression levels of PoMDR genes in the stem and cap were examined for the first time and it was determined that the expression levels of these genes had similar profiles, but the expression levels of these genes were higher in the cap.
\end{abstract}

Keywords: ABC cassette transporters, MDR subfamily, mRNA expression, Pleurotus ostreatus, Oyster mushroom

\section{Atıf için (Cite);}

Düzel, H.K., Aydemir, B.Ç. (2021). Kayın Mantarı (Pleurotus ostreatus) Genomunda Bulunan ABC Proteinlerinden MDR Alt Ailesinin Biyoinformatik Analizi ve İfade Profili, Recep Tayyip Erdogan University Journal of Science and Engineering, 2(2), 72-82. Doi: 10.53501/rteufemud.1017979 


\section{Giriş}

Şapkalı mantarlar, humuslu ve nemli toprakları tercih eden, toprak altında olabileceği gibi toprak üzerinde de gelişme gösteren makrofunguslardır (Chang ve Miles, 1992). Görünüşleri, yapıları ve gelişimlerindeki farklılıklara bağlı olarak Basidiomycota veya Ascomycota bölümleri içinde yer alan makrofunguslar, yenilebilir, yenilemez, tıbbi ve zehirli türleri içerirler (Stamets ve Chilton, 1985). Bunlar arasında, şapkalı mantar türlerinin sayısının 140,000 olduğu tahmin edilmektedir (Wasser, 2002). 2019 FAO verilerine göre Türkiye'de Kültür mantar1 üretim miktar1 49.364 ton/y1l olarak vermiştir. Ancak ülkemiz kültür mantarı ticaretinde kayıt dışı üretim oranı azımsanmayacak bir oranda olup, toplam mantar üretiminde kullanılan ithal ve yerli misel miktarları ile ticari olarak satılan kompost miktarları göz önünde bulundurulduğunda (Eren ve Pekşen, 2019)'a göre 2018 ülkemiz mantar üretim miktarı yaklaşık 65.000 ton olarak belirtilmiştir. Dünyada kültür mantarı üretiminde ilk sırayı alan ülke 8.948.099 ton/yıl ile Çin Halk Cumhuriyetidir (FAO, 2019).

Mantarların kuru madde üzerinden $\% 50$ ila 65 'i karbonhidrat, \%19-35'i proteinler ve \%2 ila 6's1 ise yağdan oluşmaktadır. Yağ asitleri yönünden mantarlar incelendiğinde ise oleik asit, linoleik asit gibi doymamış yă asitleri ve özellikle palmitik asit gibi doymuş yağ asitlerinin öne çıktığ 1 görünmektedir. Yağda çözünen vitaminlerle beraber ergosterol içerikleri de zengin olan mantarların, aynı zamanda, D vitamini açısından da tek vejetaryan kaynak olarak gösterilmektedir (Stamets ve Chilton, 1985). Mantarlar sadece yukarıda bahsedilen bu özellikleri bakımından değil, özellikle tıbbi çalışmalarda kullanılıp başarı göstermelerinden dolayıda dünya üzerinde oldukça önemli bir yere sahiptirler (Pekşen, 2013; Wasser, 2010).

ABC Proteinlerine aynı zamanda ATP Bağlayan Kaset Taşıyıcıları veya bir diğer deyişle $A B C$ Taşıyıcıları isimleri de verilmiştir (Fath ve Kolter, 1993; Rea, 2007; Rea vd., 2003). ABC proteinlerinin temel olarak iki adet NBD
(Nükleotid Bağlanma Alanı) ile birlikte iki adet de TMD (Transmembran Alanı) olmak üzere toplam dört birimden oluştuğu bildirilmiştir (Varadi vd., 2003). Membranının iç kısmında yaklaşık olarak altı $\alpha$-heliks dönüşlük bir alanı kaplayan TMD hidrofobik özellikte olan amino asitlerden oluşmaktadır (Varadi vd., 2003; Oswald vd., 2006).

Arabidopsis thaliana ve Oryza sativa genomlarının yayımlanmasının ardından yapilan analizler sonucunda, ABC Kaset Taşıyıcı proteinlerinin yapısal farklılıklarına ve başlıca görevlerine göre on üç alt aileye ayrıldığ 1 bildirilmiştir (Sanchez-Fernandez vd., 2001; Rea vd., 2003; Schulz ve Kolukisaoglu, 2006; Rea, 2007; Yazaki vd., 2009). Daha sonra yapilan çalışmalarda insan homologları ile yapısal özelliklerinin benzerlikleri de dikkate alınarak A'dan I'ya kadar uzanan farklı alt kategorilere ayrıldığı belirlenmiştir (Theodoulou, 2000; Sanchez-Fernandez vd., 2001; Rea vd., 2003; Vasiliou vd., 2008; Yazaki vd., 2009).

Hücre ve organellerin membranlarında yer aldığ bildirilen $\mathrm{ABC}$ proteinleri temel olarak hücre içi ve dış çevresi ile olan madde alışverişinden sorumludurlar. Ancak, bununla birlikte nükleik asitlerin ve kromozom yapısının düzenlenmesi, sinyal iletimi, protein salınımı ve ilaç direnci gibi diğer birçok metabolik olaylarda da görev aldıkları belirlenmiştir (Fath ve Kolter, 1993; Higgins ve Linton, 2003). Araştırmacılar bu protein ailesinin bitkilerdeki görevlerinin insan ve bakterilerde olduğu gibi ilaç direnci ile sınırlı olduğunu düşünseler de, devam eden araştırmalar, bu proteinlerin, aynı zamanda bitkilerde çok farklı metabolik olaylarda önemli roller üstlendiklerini göstermektedir (Kang vd., 2010; Rea, 2007; Rea vd., 2003).

ATP bağlayıcı kaset (ABC), substratların ATPaz alt ünitesini kullanarak hücre membranı boyunca translokasyonunu kolaylaştırır (Wang vd., 2017). $\mathrm{Bu}$ taşıyıcı aile insanlarda çoklu ilaç direnci, antijen işleme, bağışıklık, lipid homeostazı, hematopoezde kilit ve hücre proliferasyonu rollere sahip olduğu kanıtlanmıştır (Wang vd., 2017). Bunun yanında ABC kaset taşıyıcılarının 
bitkilerde, bitki gelişimi, tohum gelişimi, tohum çimlenmesi, organ oluşumu ve ikincil büyüme gibi süreçlerde görev aldığı bildirilmiştir (Yazaki vd., 2009). ABC taşıyıcılarının, fitohormonların taşınmasında rolleri de dahil olmak üzere bitkilerin büyümesi ve gelişmesinde de aldığı roller bilinmektedir.

$\mathrm{ABC}$ proteinlerinin en önemli alt ailelerinden birisi $\mathrm{ABCB}$ olarak isimlendirilen ailedir. $\mathrm{Bu}$ ailede olduğu bildirilen iki protein grubu vardır. Bunlardan birincisi ve en önemlisi MDR (Multi Drug Resistance) proteinleri olup, bunlar tam molekül yapıları ile bilinmektedirler. Diğer grup ise yarım moleküler yapıya sahip olan TAP (Transporter associated with Antigen Processing) ve ATM (ATP-binding cassette transporter of the Mitochondria) proteinleridir (Dean vd., 2001). MDR proteinleri ilk olarak insan kanser hücrelerinde aşırı ekspresyonunda çoklu ilaç etkisine karşın direnç göstermesinden dolayı bu isim verilmiştir. Ökaryotik sınıflandırma içerisinde $\mathrm{ABCB}$ ailesi içerisinde yer alan MDR, TMD1-NBD1-TMD2-NBD2 yapısına sahip ileri yönlü (forward-orientation) ve yaklaşı 1200 amino asit büyüklüğünde olan proteinleri içermektedir (Rea vd., 2003; Rea, 2007). ABCB/MDR alt ailesi (P-Glikoprotein Homologları) 22 tane Arabidopsis thaliana'da, 24 tane de çeltik (Oryza sativa) genomunda (Garcia vd., 2004) ve 28 adetde Vitis vinifera genomunda (Çakır vd., 2013) bulunarak bitkilerde ikinci en büyük alt aileyi ve en büyük tam-taşıyıcı (full transporter) alt ailesini oluşturmaktadır.

Arabidopsis bitkisinde Dudler ve Hertig (1992) tarafından yapılan bir çalışmada $\mathrm{ABCB}$ protein ailesine ait olan ve AtABCB1 olarak isimlendirilen bir genin öncelikli olarak savunma mekanizmasında görev aldığ 1 düşünülmüş, ancak daha sonra yapılan araştırmalar sonucunda bir bitki hormonu olan oksinin taşınmasında fonksiyonel olarak görev aldığı gösterilmiştir. Aynı şekilde AtABC19 proteinininde oksin taşınmasında görev aldığı ve bu proteini kodlayan genin susturulması durumunda ise yaprak morfolojisi farklı ve aynı zamanda bodur bitkilerin geliştiği gösterilmiştir (Noh vd., 2001). Yine Arabidopsis bitkisinde bu gen ailesinin diğer üyeleri ile yapılan çalışmalar bu proteinlerin aynı zamanda farklı biyolojik süreçlerde de rollerinin olduğunu göstermiştir. AtABCB14 geninin $\mathrm{CO}_{2}$ değişimine bağlı olarak stomaların kapanmasinda (Lee vd., 2005) ve AtABCG25, AtABCG40, AtNPF4.6 ve AtDTX50 genlerininde absisik asit (ABA) taşınımında rol aldıkları belirlenmiştir (Kuromori vd., 2018).

Diğer bitkilerde bu proteinlerle ilgili olarak yapılan çalışmalar incelendiğinde ise bu proteinlerin Coptis japonica'da berberin, patateste ve buğdayda ise calmodulin taşınımından sorumlu olduğu bildirilmiştir (Rea, 2007). Wang vd. (2017) yaptıkları çalışmada ise patates bitkisinden izole edilen PMDRl geninin bitkide kalsiyum taşınmasında rol oynadığını göstermiştir. Maya hücrelerinde (S. cerevisiae) ifade edilen Ste6p ABC proteininin görevinin ise peptit feromon taşınması olduğu bildirilmiştir (Jungwirth ve Kuchler, 2005).

Bitki ve hayvanlarda $A B C$ kaset taşıyıcıları ve görevleri hakkında çeşitli bilgilere sahipken mantarlarda bu çalışmalar oldukça sınırlıdır. Bu nedenle de yapılmış olan bu çalışma kapsamında gelecekte yapılan çalışmalara katkı sağlaması açısından bu protein ailesinin, ekonomik değeri yüksek olan kayın mantarında ( $P$. ostreatus) biyoinformatik analizler kullanılarak tanımlanması ve fonksiyonlarının anlaşılması amaçlanmıştır.

\section{Materyal ve Metot}

\subsection{Materyal}

$\mathrm{Bu}$ çalışmada kullanılan Kayın Mantarı (Pleurotus ostreatus) bitkisel materyali, İzmir mantar işletmesi bünyesinde Foça'da faaliyet gösteren Baba Mantar işletmesinden temin edilmiştir. Ülkemizde $P$. ostreatus en çok Kayın mantarı olarak bilinmesine karşın, Kavak mantarı, İstiridye mantarı veya Yaprak mantarı gibi isimlerle de anılmaktadır (Pekşen, 2013). Mantarlar ilk flaş döneminin ikinci günü ve oda 
dolumunun $\quad$ 46. gününde (03.06.2018) toplanmıştır.

\subsection{Pleurotus ostreatus Genomunda ABC Taşıyıcı Genlerinin Belirlenmesi}

Yeni nesil dizileme (NGS) ve Bionano optik haritalama yöntemleri kullanılarak $34.76 \mathrm{Mb}$ büyüklüğündeki $P$. ostreatus genomu dizisi elde edilmiştir. $\mathrm{Bu}$ genom içerisinde toplam 20 $M Y B$ geni (PoMYB) genom boyunca tanımlanmış ve tam uzunlukta açık okuma çerçeveleri belirlenmiştir.

P.ostreatus genomunda olas1 ABC kaset taşıyıcılarının biyoinformatik analizinde öncelikle Kovalchuk vd. (2015)'nin diğer fungus türlerinde tanımlamış olduğu protein sekansları kullanılmıştır. Basidiomiset grubundaki tam moleküllü MDR alt protein ailesine ait protein dizileri 'Pleurotus ostreatus genom browser' veri tabanı kullanılarak BLAST (Basic Local Alignment Search Tool - Temel Yerel Hizalama Arama Aracı) analizi yapılmış ve sekanslar elde edilmiştir. Elde edilen sekansların yarım molekül TMD ve tam molekül MDR ayrımını sağlamak için NCBI (National Center for Biotechnology Information) veritabanı kullanılarak motif taraması yapılmış ve tam molekül MDR alt ailesine ait genler tespit edilmiştir.

\subsection{Filogenetik ve Motif Analizi}

Elde edilen tam molekül MDR alt ailesine ait gen dizileri Mega7 (Tamura vd., 2011) programı kullanılarak hem test edilmiş hem de filogenetik ağaç oluşturulmuştur. Yine bu aşamada Motif Scan (https://myhits.isb-sib.ch/cgibin/motif_scan) veritaban1 yardımı ile proteinlerin olası fonksiyonları araştırılmıştır.

\subsection{RNA İzolasyonu}

RNA izolasyonu için Zhu vd. (2017)'nin bildirmiş oldukları toplam RNA izolasyonu protokolü izlenmiştir. Sap ve şapkalardan 160 mg örnek alınarak $600 \mu 1$ tampon çözeltisi $(\mathrm{pH}$ 9'da $50 \mathrm{mM}$ Tris, $5 \mathrm{mM}$ ETDA, $150 \mathrm{mM} \mathrm{LiCI}$, ve $\% 5 \mathrm{SDS}$ ) ilave edilmiş ve vorteks ile karıştırılarak $35 \quad \mathrm{dk} . \quad 10.000 \quad \mathrm{rpm} \quad \mathrm{de}$ santrifüjlenmiştir. Üst faz alınarak fenol/klorofom/ izoamil alkol (25:24:1) ilave edilerek vortekslenmiş ve santrifüjden geçirilmiştir. Elde edilen üst faz alınarak $10 \mathrm{Mm}$ $\mathrm{LiCl}$ ilave edilemiş ve toplam RNAlar çöktürülmüştür. Çöken RNAlar \%70' lik etanol ile yıkanarak saf su içinde çözdürülmüştür. Jele yüklenerek miktarı ve kalitesi kontrol edilen RNA'ların, kullanılacak miktarı belirlendikten sonra DNA'dan arındırılmaları için DNase I RNase Free (Thermo, Waltham, Massachusetts, ABD) enzimi ile muamele edilerek genomik DNA, toplam RNA'dan uzaklaştırılmıştır. Elde edilen RNA'nın, DNase enzimi, parçalanmış DNA veya kalıntılarından ve tuzlar'dan temizlenmesi amaciylada "RNeasy MinElute Cleanup Kit (Qiagen, Hilden, Germany)" kiti üretici firmanın önerileri doğrultusunda kullanılmıştır.

\section{5. cDNA Sentezi}

Elde edilen toplam RNAlar, cDNA sentezi eldesinde kullanılmıştır. Toplam RNA'lar dan (Fermentas, Waltham, Massachusetts, ABD), üretici firmanın protokolleri izlenerek cDNA sentezi gerçekleştirilmiştir.

\subsection{Real-Time Poymeraz Zincir Reaksiyonu (Polymeraz Chain Reaction, PCR) Analizleri}

Real Time PCR reaksiyonları Ege Üniversitesi, Ziraat Fakültesi, Merkez Laboratuvarı'nda Rotor Gene Q Real Time PCR (Qiagen, Hilden, Germany) cihazında gerçekleştirilmiştir. Biyoinformatik analizler kullanılarak karakterize edilmiş MDR alt ailesine ait genlerin dizi bilgileri üzerinden primerler tasarlanmıştır (Tablo 1). Real Time Reaksiyonu için; $1 \mu \mathrm{L}$ cDNA, 12,5 $\mu \mathrm{L}$ SYBR ${ }^{\circledR}$ Green Master Mix (2X), $2 \mu \mathrm{L}$ Forward ve $2 \mu \mathrm{L}$ Reverse primer (10 $\mu \mathrm{M})$ ve $7,5 \mu \mathrm{L} \mathrm{dH}_{2} \mathrm{O}$ tüplere total hacim $25 \mu \mathrm{L}$ olacak şekilde amplifikasyon gerçekleştirilmiştir. 
Tablo 1. Çalışmada kullanılan primerlerin dizilimi

Table 1. Primers used in the study

\begin{tabular}{|c|c|c|c|c|}
\hline Sira & Primer adı & Primer dizisi & $\overline{T M}$ & $\overline{(b p)}$ \\
\hline \multirow{2}{*}{1} & PoMDR $1 \mathrm{~F}$ & CCATGACGCCCGTCTTCTCC & $58^{\circ} \mathrm{C}$ & 20 \\
\hline & PoMDR1R & TGACCCACGAAGAGGCGAGA & $62^{\circ} \mathrm{C}$ & 20 \\
\hline \multirow{2}{*}{2} & PoMDR2F & CCATGACGCCCGTCTTCTCC & $60^{\circ} \mathrm{C}$ & 20 \\
\hline & PoMDR2R & CGATGCCGCCAAAGGTGTTG & $60^{\circ} \mathrm{C}$ & 20 \\
\hline \multirow{2}{*}{3} & PoMDR3F & CATCGGGCTGGTTACCGCAT & $60^{\circ} \mathrm{C}$ & 20 \\
\hline & PoMDR3R & GTTGCGTCTGCATCGCCTTG & $58^{\circ} \mathrm{C}$ & 20 \\
\hline \multirow{2}{*}{4} & PoMDR4F & GTACCTCCGCCTTGGATGCC & $58^{\circ} \mathrm{C}$ & 20 \\
\hline & PoMDR4R & CAACACGGCCCTCGTCTACC & $60^{\circ} \mathrm{C}$ & 20 \\
\hline \multirow{2}{*}{5} & PoMDR5F & ACCTCAGCATCGAGCATGGC & $62^{\circ} \mathrm{C}$ & 20 \\
\hline & PoMDR5R & GCGCAGCGATTGTGGACTTG & $60^{\circ} \mathrm{C}$ & 20 \\
\hline \multirow{2}{*}{6} & PoMDR6F & AACTCGTGCACGCCCAGAAA & $58^{\circ} \mathrm{C}$ & 20 \\
\hline & PoMDR6R & GGGCCTGCTTCTCCATGTCC & $58^{\circ} \mathrm{C}$ & 20 \\
\hline \multirow{2}{*}{7} & PoMDR7F & CATCGGGCTGGTTACCGCAT & $60^{\circ} \mathrm{C}$ & 20 \\
\hline & PoMDR7R & GTTGCGTCTGCATCGCCTTG & $58^{\circ} \mathrm{C}$ & 20 \\
\hline \multirow{2}{*}{8} & PoMDR8F & TACGCAAGTAGGCGGCAAGG & $58^{\circ} \mathrm{C}$ & 20 \\
\hline & PoMDR8R & GGCGATCGCAATGCGTTGTT & $58^{\circ} \mathrm{C}$ & 20 \\
\hline \multirow{2}{*}{9} & PoMDR9Factin & TGCTGGTCGTGACCTTACCG & $62^{\circ} \mathrm{C}$ & 20 \\
\hline & PoMDR9Ractin & AGCTCTTCTCCAGGGCGGAT & $62^{\circ} \mathrm{C}$ & 20 \\
\hline
\end{tabular}

\section{Bulgular ve Tartışma}

\subsection{Pleurotus osteratus ABCB Protein Ailesine Ait Bulgular}

Referans ABCB protein dizileri (Kovalchuk vd., 2015) kullanılarak yapılan analizler sonucunda 16 adet $\mathrm{ABCB}$ protein ailesine ait protein dizisi elde edilmiştir. Yapılan bu çalışmada elde edilen sekansların sekiz tanesinin yarım molekül TMD, diğer sekiz tanesinin ise tam molekül MDR oldukları belirlenmiştir. $\mathrm{Bu}$ çalışmada tam molekül MDR genleri kullanılmıştır. MDR alt ailesinin üyelerinin isimlendirilmesi daha önceki çalışmalar baz alınarak yapılmıştır. Bu çalışmada belirlenen tam molekül PoMDR alt ailesinin 8 üyesi ile ilgili genom, gen ve protein özellikleri Tablo 2'de gösterilmektedir.

PoMDR alt ailesinde sekiz farklı genin beş farklı kromozom üzerinde $(4,5,8,24$ ve 28$)$ lokalize olduğu saptanmıştır. PoMDR genleri içerisinde en uzun okuma çerçevesine sahip PoMDR8 geni iken, en kısa okuma çercevesine sahip PoMDR4 geninin olduğu belirlenmiştir. Protein yapısı incelendiğinde ise $P O M D R$ alt ailesinin büyük proteinlerden oluştuğu görülmüştür. $\mathrm{Bu}$ çalışmada belirlenen 8 tam molekül MDR alt aileleri ile ilgili topolojilerin tümü (TMD-NBD)2 olarak belirlenmiş ve her alt ailenin protein adları yine Tablo 2'de açık olarak verilmiştir. 
Tablo 2. Tam Molekül PoMDR Alt Ailesi üyelerinin sahip olduğu genom, gen ve protein özellikleri

Table 2. Genome, gene, protein characteristics of full length PoMDR subfamily members

\begin{tabular}{|c|c|c|c|c|c|c|c|c|c|c|c|c|}
\hline Alt aile adı & Alt aile adı & Topoloji & CDS & Pleurotus osteratus protein adı & $\begin{array}{l}\text { Protein } \\
\text { ID }\end{array}$ & Strand & Lokasyon & Exon & $\begin{array}{l}\text { Transcript } \\
\text { Uzunluğu }\end{array}$ & $\mathbf{A A}$ & pl & mW (Da) \\
\hline PoMDRl & PoABCBI & $\begin{array}{l}\text { (TMD- } \\
\text { NBD) } 2\end{array}$ & Tam & estExt_fgenesh2_pg.C_11107 & 175376 & + & $\begin{array}{l}1: 4435918 \text { to } \\
4442729\end{array}$ & 8 & 6812 & 1883 & 8.68 & 205888.78 \\
\hline PoMDR2 & PoABCB2 & $\begin{array}{l}\text { (TMD- } \\
\text { NBD) } 2\end{array}$ & Tam & genemark.1594_g & 153729 & + & $\begin{array}{l}1: 4437665 \text { to } \\
4442459\end{array}$ & 4 & 4795 & 1544 & 7.52 & 167843.01 \\
\hline PoMDR3 & РоABCB3 & $\begin{array}{l}\text { (TMD- } \\
\text { NBD) } 2\end{array}$ & Tam & e_gw1.7.692.1 & 32010 & - & $\begin{array}{l}7: 1318591 \text { to } \\
1323781\end{array}$ & 24 & 5191 & 1320 & 6.20 & 143049.19 \\
\hline PoMDR4 & PoABCB4 & $\begin{array}{l}\text { (TMD- } \\
\text { NBD) } 2\end{array}$ & Tam & estExt_Genewise1.C_12691 & 43044 & + & $\begin{array}{l}1: 4437791 \text { to } \\
4442729\end{array}$ & 5 & 4969 & 1354 & 6.64 & 146428.72 \\
\hline PoMDR5 & PoABCB5 & $\begin{array}{l}\text { (TMD- } \\
\text { NBD) } 2\end{array}$ & Tam & fgenesh2_pg.1_\#_1118 & 165012 & + & $\begin{array}{l}1: 4435918 \text { to } \\
4442459\end{array}$ & 8 & 6542 & 1883 & 8.68 & 205888.78 \\
\hline PoMDR6 & РоABCB6 & $\begin{array}{l}\text { (TMD- } \\
\text { NBD) } 2\end{array}$ & Tam & genemark.8090_g & 160225 & - & $\begin{array}{l}7: 1318591 \text { to } \\
1323781\end{array}$ & 24 & 5191 & 1319 & 6.13 & 149928.05 \\
\hline PoMDR7 & РоABCB7 & $\begin{array}{l}\text { (TMD- } \\
\text { NBD)2 }\end{array}$ & Tam & gw.1.7.535.1 & 6711 & - & $\begin{array}{l}7: 1318660 \text { to } \\
1323772\end{array}$ & 24 & 5173 & 1315 & 6.12 & 142431.47 \\
\hline PoMDR8 & РоABCB8 & $\begin{array}{l}\text { (TMD- } \\
\text { NBD)2 }\end{array}$ & Tam & fgenesh2_pg.7_\#_320 & 169568 & - & $\begin{array}{l}7: 1316880 \text { to } \\
1323781\end{array}$ & 28 & 6902 & 1689 & 5.80 & 182640.01 \\
\hline
\end{tabular}




\subsection{Pleurotus osteratus MDR Proteinlerinin} Filogenetik Analizi

Yapılan filogenetik analiz sonucunda $P o M D R$ alt ailesinin üyeleri Amanita muscaria Koide (amanuABCB1.1) ile ortak atadan dallandığı, sebve ve pirin türleriyle yakınlık gösterdiğ görülmüştür. PoMDR alt ailesi ve bu çalışmada referans olarak kullanılan diğer mantar türlerinin filogenetik ağacı Şekil 1'de, Pleurotus osteratus
MDR alt ailesinin filogenetik ağacı ise Şekil 2'de gösterilmektedir. Filogenetik analiz sonucunda PoMDR1-PoMDR2-PoMDR4-PoMDR5 ve PoMDR8-PoMDR7-PoMDR6-PoMDR3 ayr1 iki dallanma göstermiştir. Daha sonra evrimsel olarak PoMDR1-PoMDR2, PoMDR5-PoMDR4 ve PoMDR7-PoMDR8 genlerinin kendi aralarında birbirlerine daha yakın oldukları belirlenmiştir (Şekil 2).

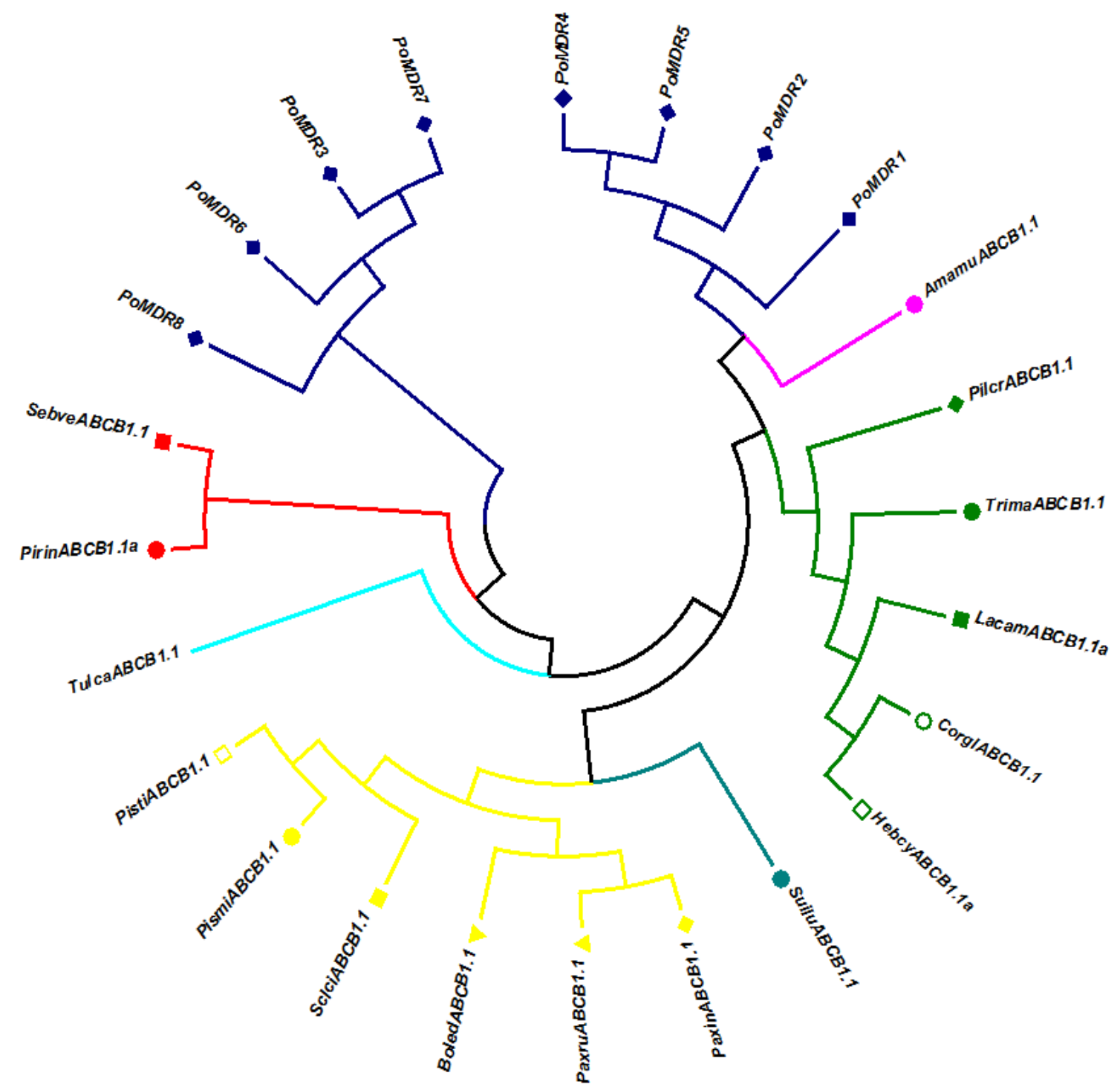

Şekil 1. Pleurotus osteratus MDR alt ailesi ve referans olarak kullanılan diğer mantar türlerinin filogenetik ağacı

Figure 1. Phylogenetic tree of Pleurotus osteratus MDR subfamily members and used reference MDRs from other fungi 


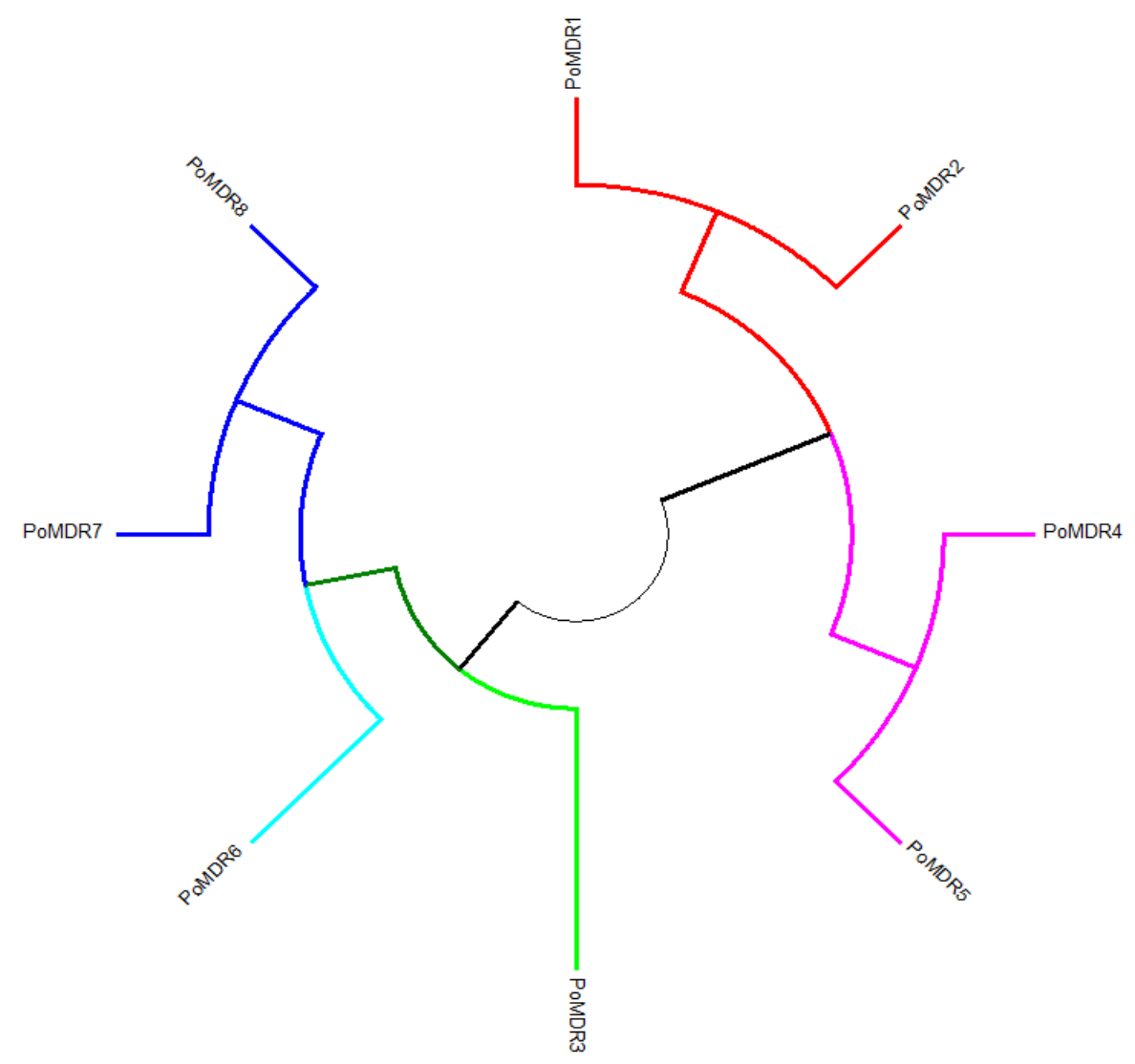

Şekil 2. Pleurotus osteratus MDR alt ailesinin filogenetik ağaci.

Figure 2. Phylogenetic tree of Pleurotus osteratus MDR subfamily members

\subsection{PoMDR Gen Ailesine Ait İfade Analizleri}

PoMDR genlerinin sap ve şapkadaki ifade düzeyleri Şekil 3'te gösterilmektedir. Alınan sonuçlar genel olarak incelendiğinde PoMDR genlerinin sap ve şapkadaki ifade düzeylerinin benzerlikler gösterdiği ve aynı zamanda bu genlerin ifadelerinin şapka kısmında, sapa oranla daha fazla olduğu tespit edilmiştir. Elde edilen qRT-PCR sonuçlarına göre PoMDRl geninin ifadesinin şapka kısmında sapa oranla dört kat arttı̆̆ görülmüştür. Yapılan motif analizinde (Motif Scan) PoMDR1 geninin B12 vitamini taşınımında görevli motif içerdiği saptanmıştır. Ayrıca, PoMDR1 geni "Bipartit nükleer lokalizasyonu" sinyali taşımaktadır ve buna bağlı olarak da bu genin çekirdekte lokalize olduğu ve görev yaptığı düşünülebilir.

PoMDR2 geninin ifadesinin şapka kısmında, sapa oranla iki kat artış gösterdiği belirlenmiştir.
Pleurotus osterous, B12 vitaminince zengin bir mantardır (Correa vd., 2016). PoMDRl geni gibi POMDR2 genininde aynı motifi içerdiği görülmüş ve motif benzerliğinden yola çıkılarak PoMDR grubu üyelerinin $\mathrm{B} 12$ vitamini taşınımında görev aldığ düşünülebilir. PoMDR3 geninin motif analizi yapıldığında, ilk iki gen gibi bu geninde B12 vitamininin taşınımı için aynı motife sahip olduğu belirlenmiştir.

POMDR4 geninin ifade profili incelendiğinde ise bu genin ifadesinin de sapa oranla, şapkada yüksek olduğu ve hatta diğer genlerle karşılaştırıldığında bu ifade düzeyinin çok daha yüksek olduğu görülmüştür. Pleurotus ostreatus mantarının şapka kısmının sekonder metabolitlerce oldukça zengin olduğu bilinmektedir (Beltran-Garcia vd., 1997). Ayrica MDR grubunun sekonder metabolitlerin taşınmasında görev yaptığı da bilinmektedir 
(Carrasco-González vd., 2017). Bu nedenlede, PoMDR4 geninin ifadesinin sapa oranla, şapkada çok daha yüksek olması PoMDR4 geninin
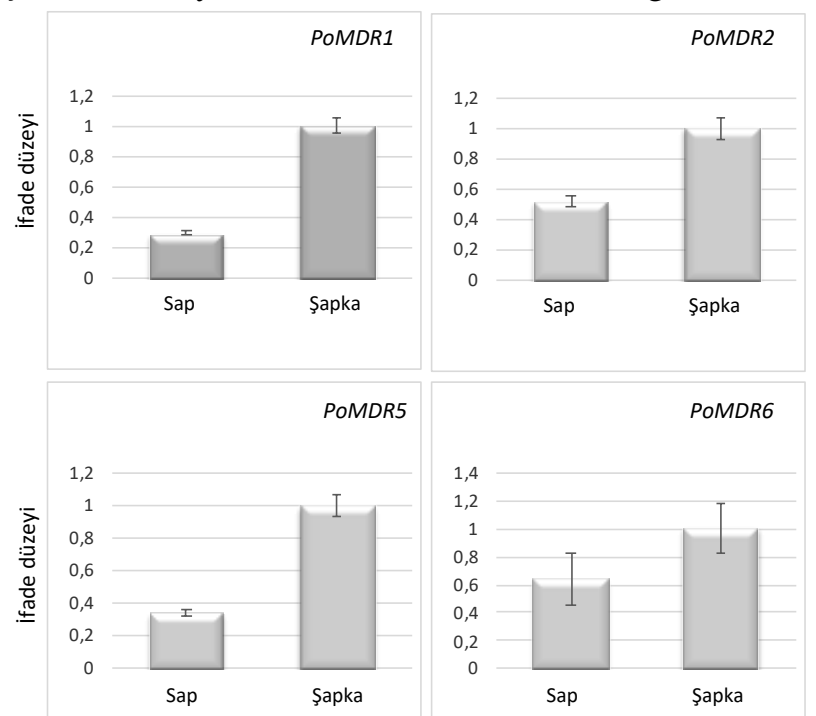

sekonder metabolit alabileceğini taşınımında görev düşündürmektedir.

Şekil 3. PoMDR alt ailesine ait genlerinin qRT-PCR analizlerine göre ifadesi Figure 3. Expression of PoMDR subfamily genes by qRT-PCR analysis

PoMDR5 geninin ifadesi incelendiğinde ise yine diğer genlerde olduğu gibi şapkada çok daha yüksek düzeyde ifade gösterdiği tespit edilmiştir (Şekil 3). Ayrıca, yapılan motif analizlerinde "Bipartit nükleer lokalizasyonu" sinyali taşıdığı belirlenmiştir. Bu nedenle de bu genin çekirdekte localize olduğu ileri sürülebilir.

PoMDR6 geninin ifade profilini incelediğimizde ise bu geninde diğer PoMDR genleri ile ifade düzeyleri yönünden benzerliklere sahip olduğu gibi şapkada ifade düzeyinin fazla olduğu söylenebilir. Ancak bu genin sapta olan ifade düzeyi, diğer PoMDR genlerinin aynı organdaki ifade düzeylerinden çok daha fazla olduğu görülmüştür (Şekil 3).

PoMDR7 geninin ifadesi incelendiğinde ise yine bu geninde, diğer üyelerle benzer şekilde, şapkada çok daha yüksek düzeyde ifade gösterdiği ve "Bipartit nükleer lokalizasyonu" sinyali taşıdığı tespit edilmiştir (Şekil 3). MDR alt ailesinin mayada yapılan çalışmalarda feromon taşınmasında görev aldığı bildirilmiştir (Michaelis ve Barrowman, 2012). Nukleusla ilişkili sinyal metabolizmasında özellikle feromon taşınmasında PoMDR1, PoMDR5 ve
PoMDR7 genlerinin görev alabileceği düşünülebilir.

PoMDR8 geninin ifade düzeyi de diğer PoMDR genlerinin ifade profilleri ile benzerdir. Ancak PoMDR8 geninin protein yapısı incelendiğinde, methiyonin, serin, fenilalanin ve prolin yönünden zengin bölgelere sahip motifler taşıdığ belirlenmiştir. Bu motifler özellikler bakımından incelendiğinde ise bu motiflerin daha çok fibrik proteinlere bağlanma ve bu proteinlerin biyosentezinde etkili oldukları görülmüştür (Laurent vd., 2000; Williamson, 1994). Ayrica, MDR proteinlerinin peptid taşınımında da görev yaptıkları daha önce yapılan çalışmalarlada ortaya konmuştur (Jungwirth ve Kuchler, 2006). $\mathrm{Bu}$ veriler göz önüne alındığında $P o M D R$ alt ailesine ait proteinlerin, kayın mantarı gelişimi boyunca gerçekleşen lipit taşınımı, peptit taşınımı ve belirlenen motiflerin fibrik proteinlere bağlanma ve bu proteinlerin biyosentezinde görev aldıkları ve varsayılan bu fonksiyonların ileride yapılacak olan çalışmalarla aydınlatılması öngörülebilir. 


\section{Sonuçlar}

$\mathrm{Bu}$ çalışma ile Pleurotus osteratus genomu taranarak $\mathrm{ABCB}$ proteinleri biyoinformatik analizler kullanılarak belirlenmiştir. Bu genlere ait genom, gen ve protein özellikleri de saptanmıştır.

MDR alt ailesinin sekiz tane gen içerdiği saptanmıştır. Bu analizlerin yanı sıra PoMDR alt ailesine ait genlerin sap ve şapkada mRNA ifade profili çıkarılmıştır. Motif Scan analizleriyle tespit edilen proteinlerin taşıdığı motifler belirlenmiş ve taşımış oldukları bu motiflere göre PoMDR proteinlerinin görevlerine dair tahmini bilgiler elde edilmiştir. Ayrıca yapılan real-time PCR analiz sonuçları; PoMDR genlerinin sap ve şapkada bulunan ifade profillerinin benzerlikler gösterdiği ve şapkada, sapa göre ifade düzeylerinin daha yüksek olduğu belirlenmiştir.

\section{Teşekkür}

$\mathrm{Bu}$ çalışma Kübra Düzel'in Yüksek Lisans tez çalışmasından elde edilmiştir. Kayın mantarı temini sağlayarak her türlü teknik desteği esirgemeyen Dr. Öğr. Üyesi Erkan EREN'e teşekkür ederiz. Bu çalışma Ege Üniversitesi Bilimsel Araştırma Projeleri Koordinasyon Birimi tarafından desteklenmiştir (Proje Numarası: FY-2018-20023).

\section{Kaynaklar}

Beltran-Garcia, M.J., Estarron-Espinosa, M., Ogura, T. (1997). Volatile compounds secreted by the oyster mushroom (Pleurotus ostreatus) and their antibacterial activities. Journal of Agricultural and Food Chemistry, 45(10), 40-49. Doi: 10.1021/jf960876i

Carrasco-González, J.A., Serna-Saldívar, S.O., Gutiérrez-Uribe, J.A. (2017). Nutritional composition and nutraceutical properties of the Pleurotus fruiting bodies: Potential use as food ingredient. Journal of Food Composition and Analysis, $\quad 58, \quad 69-81$. http://dx.doi.org/10.1016\%2Fj.jfca.2017.01.016

Chang S. T., Miles P.G. (1992). Mushroom biologya new discipline. The Mycologist, 6, 64-65. Doi: http://dx.doi.org/10.1007/s00253-010-3022-4
Correa, R.C.G., Brugnari, T., Bracht, A., Peralta, R.M., Ferreira, I.C.F.R. (2016). Biotechnological, nutritional and therapeutic uses of Pleurotus spp. (Oyster mushroom) related with its chemical composition: A review on the past decade findings. Trends in Food Science \& Technology, 50, 103e117 Doi: 10.1016/j.tifs.2016.01.012

Çakır, B., Kılıçkaya, O. (2013) Bitkilerde atp bağlı kaset (abc) taşıyıcı proteinlerinin yapısal özellikleri. Adnan Menderes Üniversitesi Ziraat Fakültesi Dergisi, 9(1), 39-44.

Dean, M., Rzhetsky, A., Allikmets, R. (2001). The human ATP-binding cassette (ABC) transporter superfamily. Genome Research, 11(7), 1156-66. Doi: $10.1101 /$ gr.184901

Dudler, R., Hertig, C. (1992). Structure of an mdr-like gene from Arabidopsis thaliana, Evolutionary implications. Journal of Biological Chemistry, 267, 5882-5888. Doi: https://doi.org/10.1016/S0021-9258(18)42636-1

Eren, E., Pekşen A. (2019). Türkiye'de Kültür Mantarı Üretimi ve Teknolojik Gelişmeler. Mantar Dergisi (Journal of Fungus), 10, 225-233.

FAO (2019). The state of Food and Agriculture. www.fao.org

Fath, F.J. and Kotler, R. (1993). ABC transporters: bacterial exporters. Microbiology Review, 57, 9951017. Doi: 10.1128/mr.57.4.995-1017.1993

Higgins, C.F., Linton, K.J. (2003). The ATP switch model for ABC transporters. Nature Structural Molecular Biology, 11, 918-926. Doi: https://doi.org/10.1038/nsmb836

Garcia, O., Bouige, P., Forestier, C., Dassa, E. (2004). Inventory and comparative analysis of rice and Arabidopsis ATP-binding cassette (ABC) systems. Journal of Molecular Biology, 343(1), 249-65. Doi: 10.1016/j.jmb.2004.07.093.

Jungwirth, H., Kuchler, K. (2006). Yeast ABC transporters-- a tale of sex, stress, drugs and aging. FEBS Letters, 580(4), 1131-8. Doi: 10.1016/j.febslet.2005.12.050.

Kang, J., Hwang, J.U., Lee, M., Kim, Y.Y., Assmann, S.M., Martinoia, E., Lee, Y. (2010). PDR-type $\mathrm{ABC}$ transporter mediates cellular uptake of the phyto hormone abscisic acid. Proceeding of the National Academy of Science of the United States of America, 107, 2355-2360. Doi: 10.1073/pnas.0909222107

Kovalchuk, A., Kohler, A., Martin, F. and Asiegbu, F.O. (2015). Diversity and evolution of ABC proteins in mycorrhiza-forming fungi. $B M C$ Evolutionary Biology, 15, 249. Doi: https://doi.org/10.1186/s12862-015-0526-7 
Kuromori, T., Seo, M. and Shinozaki, K. (2018). ABA tranport and plant water stress responses. Trends in Plant Science, 23(6), 513-522. Doi: 10.1016/j.tplants.2018.04.001

Laurent, F., Labesse, G. and Wit, P. (2000). Molecular Cloning and Partial Characterization of a Plant VAP33 Homologue with a Major Sperm Protein Domain. Biochem Biophys Res Commun, 2(1), 286-92. Doi: 10.1006/bbrc.2000.2387.

Lee, M., Lee, K., Lee, J., Noh, E. W., Lee, Y. (2005). AtPDR12 contributes to lead resistance in Arabidopsis. Plant Physiology, 138, 827-836. Doi: 10.1104/pp.104.058107

Michaelis, S., Barrowman, J. (2012). Biogenesis of the Saccharomyces cerevisiae pheromone a-factor, from yeast mating to human disease. Microbiology and Molecular Biology Review, 76, 626-651. Doi: 10.1128/MMBR.00010-12

Noh, B., Murphy, A. S., Spalding, E. P. (2001). Multidrug resistance-like genes of Arabidopsis required for auxin transport and auxin-mediated development. The Plant cell, 13(11), 2441-2454. Doi: https://doi.org/10.1105/tpc.010350

Oswald, C., Holland, I.B., Schmitt, L. (2006). The motor domains of ABC-transporters/what can structures tell us? Naunyn Schmiedebergs Arch Pharmacol, 372, 385-399. Doi: https://doi.org/10.1007/s00210-005-0031-4

Pekşen A. (2013). Mantarların insan hayatı ve sağlığındaki yeri. Bahçe Haber, 2(1), 10-15.

Rea, P.A. (2007). Plant ATP-binding cassette transporters. Annual Review of Plant Biology, 58, 347-375.

Doi: https://doi.org/10.1146/annurev.arplant.57.032905 .105406

Rea, P.A., Sánchez-Fernández, R., Chen, S., Peng, M., Klein, M., Geisler, M., and Martinoia, E. (2003). The Plant ABC Transporter Superfamily: The Functions of a Few and Identities of Many, ABC Proteins, Holland, I. B., Cole, S. P. C., Kuchler, K. ve Higgins, C. F. (Eds.), ABC proteins from bacteria to man. Academic Press, London, 335-355.

Sánchez-Fernández, R., Davies, T.G., Coleman, J.O., Rea, P.A. (2001). The Arabidopsis thaliana ABC protein superfamily, a complete inventory. Journal of Biological Chemistry, 276(32), 3023144. Doi: 10.1074/jbc.M103104200.

Schulz, B., Kolukisaoglu, H.Ü. (2006). Genomics of plant ABC transporters: The alphabet of photosynthetic life forms or just holes in membranes. FEBS letters, 580(4), 1010-1016. Doi: 10.1016/j.febslet.2006.01.002
Stamets, P., Chilton, J.S. (1985). The Mushroom Cultivator: A Practical Guide to Growing Mushrooms at Home, Richmond Publishing Co Ltd., London.

Tamura, K., Peterson, D., Peterson, N., Stecher, G., Nei, M., Kumar, S. (2011). MEGA5: Molecular evolutionary genetics analysis using maximum likelihood, evolutionary distance, and maximum parsimony methods. Molecular Biology and Evolution, 28(10), 2731-2739. Doi: https://doi.org/10.1093/molbev/msr121

Theodoulou, F.L. (2000). Plant ABC transporters. Biochimica et Biophysica Acta (BBA) - Bio membranes, 1465(1-2), 79-103. Doi: $10.1016 / \mathrm{s} 0005-2736(00) 00132-2$

Varadi, A., Tusnady, G. E., Sarkadi, B. (2003). Membrane Topology of the Human ABC Transporter Proteins. In ABC Proteins (I. B. Holland, P. C. C. Susan, K. Karl, S.P.C.C.K. Christopher) Academic press, 37-46, London

Vasiliou, V., Vasiliou, K., and Nebert, D. (2008). Human ATP-binding cassette (ABC) transporter family. Human Genomics, 3, 281-290. Doi: 10.1186/1479-7364-3-3-281

Wang, W., Buitrago, L., and Wang, Y. (2017). ABC transporters in megakaryopoiesis and platelet activity. Thrombosis Research, 156, 126-133. Doi: 10.1016/j.thromres.2017.06.020

Wasser, S.P. (2010). Medicinal mushroom science: history, current status, future trends, and unsolved problems. Int J Med Mushrooms, 12(1), 1-16. Doi:10.1615/IntJMedMushr.v12.i1.10

Wasser, S.P. (2002). Medicinal Mushrooms as a Source of Anti-tumor and immuno-modulating Polysaccharides. Applied Microbiolgy and Biotechnology, 60, 258-274. Doi: 10.1007/s00253002-1076-7

Williamson, M.P. (1994). The structure and function of proline-rich regions in proteins. Biochemistry Journal, 15(2), 249-60. Doi: 10.1042/bj2970249

Yazaki K., Shitan N., Takanashi K. (2009). Cell and molecular biology of ATP-binding cassette proteins in plants. International Review of Cell and Molecular Biology, 263-299. Doi: 10.1016/S1937-6448(09)76006-X

Zhu, H., Sun, X., Liu, D., Zheng, L., Chen, L., Ma, A. (2017). An improved total RNA extraction method for white jelly mushroom Tremella fuciformis rich in polysaccharides. Mycobiology, 45(4), 434-437. Doi:10.5941/MYCO.2017.45.4.434 